\title{
Understanding engagement in a family-focused, multicomponent, childhood weight management programme delivered in the community setting
}

\author{
Emily Kelleher ${ }^{1, *}$, Sheena M McHugh ${ }^{1}$, Janas M Harrington ${ }^{1}$, Ivan J Perry ${ }^{1}$ and \\ Frances Shiely ${ }^{1,2}$ \\ ${ }^{1}$ School of Public Health, 4th Floor, Western Gateway Building, University College Cork, Cork, Republic of Ireland: \\ ${ }^{2}$ HRB Clinical Research Facility, Mercy University Hospital, Cork, Republic of Ireland
}

Submitted 5 March 2018: Final revision received 2 0ctober 2018: Accepted 26 November 2018: First published online 6 February 2019

\begin{abstract}
Objective: To describe public health nurses' (PHN) experiences of referring to, and families' experiences of being referred to, a multicomponent, community-based, childhood weight management programme and to provide insight into families' motivation to participate in and complete treatment.

Design: Qualitative study using semi-structured interviews and the draw-and-write technique.

Setting: Two geographical regions in the south and west of Ireland.

Participants: Nine PHN involved in the referral process, as well as ten parents and nine children who were referred to and completed the programme, participated in the present study.

Results: PHN were afraid of misclassifying children as obese and of approaching the subject of excess weight with parents. Peer support from other PHN as well as training in how best to talk about weight with parents were potential strategies suggested to alleviate these fears. Parents recalled the anxiety provoked by the 'medical terminology' used during referral and their difficulty interpreting what it meant for the health of their child. Despite initial fears, concern for their children's future health was a major driver behind their participation. Children's enjoyment, the social support experienced by parents as well as staff enthusiasm were key to programme completion.

Conclusions: The present study identifies the difficulties of referring families to community weight management programmes and provides practical suggestions on how to support practitioners in making referrals. It also identifies key positive factors influencing parents' decisions to enrol in community weight management programmes. These should be maximised by staff and policy makers when developing similar programmes.
\end{abstract}

Keywords: Childhood Obesity Attendance Community
Childhood obesity is a significant public health issue worldwide $^{(1,2)}$. The current plateau is unacceptably high ${ }^{(3)}$ and the consequences for children, their families and the health service remain substantial ${ }^{(4)}$. Children who are obese are likely to remain obese through to adulthood ${ }^{(5)}$ and to develop chronic disease. Moreover, an obese child is also at increased risk of immediate co-morbidities including orthopaedic and neurological conditions, breathing disorders and psychosocial problems ${ }^{(6)}$. Childhood is therefore a critical time for the implementation of effective prevention and weight management initiatives.

Uncertainty surrounds the most effective way to manage childhood obesity in the community ${ }^{(7)}$. While international recommendations agree that programmes to treat childhood obesity should be family-focused and combine healthy eating, physical activity and behavioural components $^{(8-10)}$, their success relies heavily on family engagement and attendance ${ }^{(11)}$. With the majority of families declining referral and up to $75 \%$ of families discontinuing care, poor engagement is one of the greatest challenges facing teams tasked with implementing childhood obesity programmes ${ }^{(11-14)}$. This raises a concern regarding the sustainability of community-based programmes ${ }^{(11,13)}$.

Referral to childhood obesity programmes is a challenge for both the staff involved in referring as well as 
Table 1 Key aspects of W82GO-community: a family-focused, multicomponent, childhood weight management programme delivered in the community setting in two geographical regions in the south and west of Ireland from April 2015

\begin{tabular}{|c|c|}
\hline Aspect & Description \\
\hline Programme aim & $\begin{array}{l}\text { Reduce obesity in children with } \mathrm{BMI} \geq 98 \text { th percentile by improving children's dietary intake, physical activity levels } \\
\text { and weight status while also increasing children's quality of life and psychosocial health }\end{array}$ \\
\hline \multirow{4}{*}{$\begin{array}{l}\text { Specific programme } \\
\text { details }\end{array}$} & Twelve-month duration. Initial individual assessment to ascertain eligibility followed by two phases: \\
\hline & $\begin{array}{l}\text { Phase 1, the initial intensive phase, consisted of six weekly group sessions for both the child and their parent/carer. } \\
\text { These sessions lasted approximately } 1.5 \text { to } 2 \mathrm{~h} \text { and incorporated educational and practical sessions to increase } \\
\text { physical activity, improve nutrition and increase sleep }\end{array}$ \\
\hline & $\begin{array}{l}\text { Phase 2: upon completion of phase } 1 \text {, children returned with their parents/carers for three booster maintenance } \\
\text { group sessions at } 3,6 \text { and } 9 \text { months. These sessions aimed to encourage the family to continue with lifestyle } \\
\text { changes and mitigate the barriers to change }\end{array}$ \\
\hline & $\begin{array}{l}\text { At } 12 \text { months, the children and their parents/carers returned for a final individual assessment to document any } \\
\text { changes and make plans for sustainment }\end{array}$ \\
\hline Delivery location & $\begin{array}{l}\text { Initial assessments took place in community health-care offices while the subsequent group sessions were } \\
\text { delivered in a local sports or community centre, weekdays, between } 15.30 \text { and } 18.00 \text { hours }\end{array}$ \\
\hline Involvement & Sessions were for parents and children \\
\hline Participants & $\begin{array}{l}\text { Children were eligible if they were aged between } 5 \text { and } 7 \text { years; were obese (BMI } \geq 98 \text { th percentile); had no } \\
\text { apparent clinical problems, co-morbidities or limitations to engaging in physical activity; no use of medication } \\
\text { known to affect body weight; and had at least one parent/carer who was able to attend each of the programme } \\
\text { sessions }\end{array}$ \\
\hline Components & Physical activity, diet and nutrition, behavioural, parent education sessions, child activity sessions \\
\hline \multirow[t]{7}{*}{ Intervention facilitators } & Administrators: responsible for liaising with parents and the programme team \\
\hline & Public health nurses: responsible for referral to W82GO-community \\
\hline & Area medical officers: involved in initial assessments \\
\hline & $\begin{array}{l}\text { Dietitians: involved in initial assessments and responsible for delivering the nutritional components of W82GO- } \\
\text { community }\end{array}$ \\
\hline & $\begin{array}{l}\text { Physiotherapists: involved in initial assessments and responsible for delivering the physical activity components of } \\
\text { W82GO-community }\end{array}$ \\
\hline & $\begin{array}{l}\text { Psychologists: involved in initial assessments and responsible for the psychological/ behavioural components of } \\
\text { W82GO-community }\end{array}$ \\
\hline & $\begin{array}{l}\text { Health promotion officers: involved in both nutritional and physical activity components of W82GO-community } \\
\text { Local area management: responsible for managing the implementation of W82GO-community }\end{array}$ \\
\hline
\end{tabular}

those families identified for referral $^{(12)}$. Research has found that school nurses involved in referral fear parental reactions to hearing about their child's overweight status ${ }^{(15)}$. These reactions may be influenced by factors including parental underestimation of children's weight as well as health professionals' skills in relaying the information $^{(16)}$.

The retention of participants in childhood obesity programmes is also problematic ${ }^{(13)}$. High programme attrition is common ${ }^{(11)}$ and while it directly impacts upon the child and his/her family, it also has negative consequences for the health service. Dropout reduces the productivity of practitioners $^{(17-19)}$, contributes to increased delays for families already on waiting lists ${ }^{(19,20)}$ and increases overall health-service expenses ${ }^{(17-19)}$.

Therefore, early-phase evaluation is necessary to identify the factors hindering engagement ${ }^{(21)}$. The aims of the present study were to:

1. understand public health nurses' (PHN) and parental experiences of referring to, and being referred to, W82GO-community, a family-focused childhood weight management programme for children with obesity;

2. identify the factors that motivated families to accept PHN referral to W82GO-community; and

3. ascertain the factors that encouraged parents and children to complete W82GO-community.

\section{Methods}

\section{Context}

W82GO-community

W82GO-community was a family-focused, behaviour change pilot programme for children aged 5-7 years whose measured BMI-for-age was $\geq 98$ th percentile. It aimed to improve nutrition, increase physical activity and facilitate behaviour change ${ }^{(22)}$ over one year and was modelled on best practice recommendations ${ }^{(8-10,23)}$. The programme was offered free of charge and was delivered by a multidisciplinary team of community health professionals including dietitians, physiotherapists, PHN, psychologists, health promotion officers, area medical officers and administrators. For the current study, W82GOcommunity was implemented in two community sites (site A and site B) from April 2015 for 12 months. Both sites were chosen as they were part of a national pilot growth measurement programme and included a mix of rural and urban towns in the west and south of Ireland. Table 1 outlines key aspects of the W82GO-community programme.

\section{Referral to W82GO-community}

Referral to W82GO-community was a two-stage process. In the first instance, children's body weight and height were measured in school by PHN using standardised 


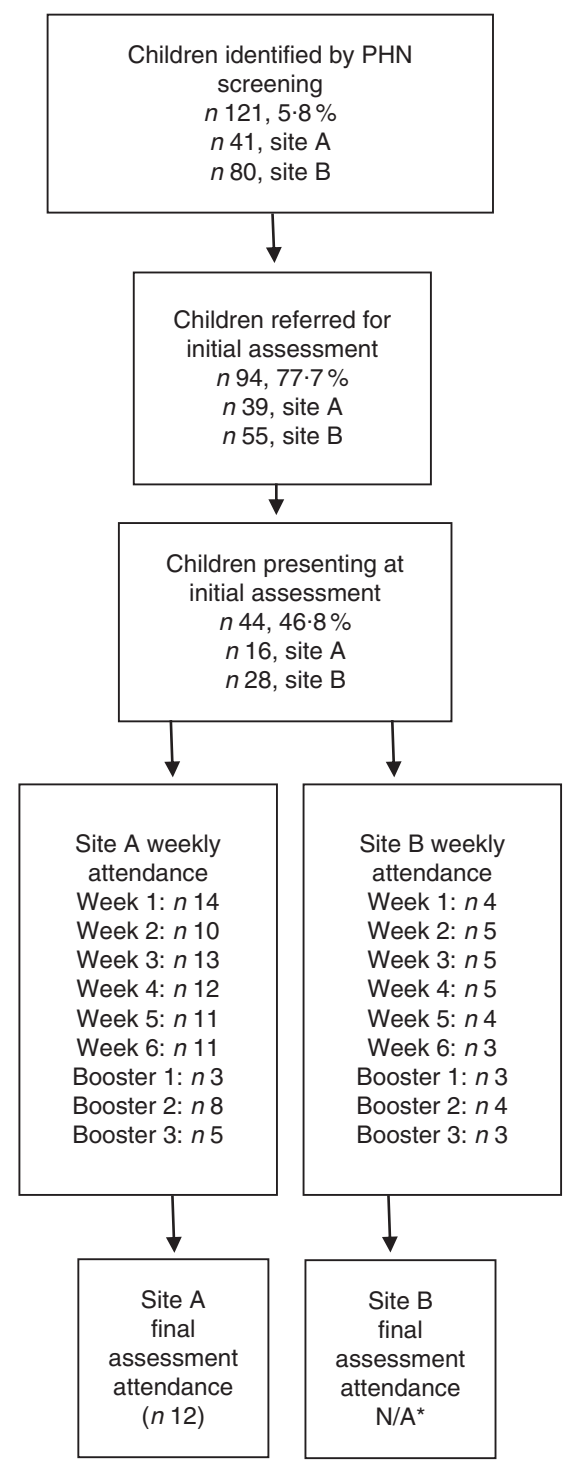

Fig. 1 Children's flow through the W82GO-community programme. *Programme staff at site B chose not to go ahead with the final assessment at 12 months due to the low numbers attending (PHN, public health nurse; N/A, not applicable)

procedures. Weight and height data were subsequently used to calculate BMI-for-age and children were classified as obese if their BMI-for-age plotted $\geq 98$ th percentile using the UK90 cut-offs ${ }^{(24)}$. PHN contacted the parents of these children, by telephone or letter, to inform them of the outcome of this screening process and to refer them to the second stage of referral: an initial assessment to ascertain programme eligibility. During initial assessment, the child and his/her parent/carer met with members of the multidisciplinary team for $1-2 \mathrm{~h}$. Families were eligible for the programme if the child was between 5 and 7 years old; measured $\geq 98$ th percentile; had no limitations to engaging in physical activity; was not taking medication known to affect body weight; and had at least one parent/ carer who was able to attend each of the programme sessions. Families who met these criteria were offered the programme. PHN were asked to conduct this screening and make referrals to W82GO-community as part of their existing roles. All PHN were invited to take part in brief training specific to the delivery of W82GO-community prior to programme commencement. Training included a needs assessment, a one-day educational training course and two days of clinical shadowing with an experienced W82GO programme practitioner. It is important to note that PHN in one of the regions received motivational interviewing workshops for childhood obesity (separate to the programme) at the time of programme implementation.

\section{Family engagement}

Out of over 2000 children measured by PHN, 121 (6\%) plotted above the 98th percentile making them potentially eligible for the programme. Of these 121, PHN invited ninety-four parents (77.7\%) to attend an initial assessment. Twenty-seven parents were not invited for initial assessment mainly because PHN could not get in touch with a parent/carer. In a few cases, there was an assumption that demand for the programme would exceed the places available and as a result some PHN chose not to refer for fear families would not be offered a place. In this instance families were referred to the community dietetic service.

By April 2016, communities in both regions (site A and site B) had completed one year of the W82GO-community pilot programme and Fig. 1 outlines families' flow through the programme. Less than half ( $n 44,47 \%$ ) of the families invited for initial assessment presented at these appointments. Following this, eighteen families (41\%) attended the first group session. In terms of attrition during the programme, four families (22\%) dropped out during phase 1 and an additional six (33\%) dropped out during phase 2 .

\section{Study design and sample}

A qualitative approach including semi-structured interviews and the draw-and-write technique ${ }^{(25)}$ was used. All PHN who referred families to W82GO-community ( $n$ 13) were invited to participate by email and followed up by telephone during which the researcher outlined the study aims and methodology. Given the likelihood that many parents would not engage in the study, all parents referred for initial assessment ( $n$ 94), including forty-two initial attenders and fifty-two non-attenders, were invited to take part in an interview. Participation was incentivised with a $€ 100$ voucher prize draw at the end of data collection. Finally, all families present at week 6 of the group sessions (n 14) received an information pack outlining the drawand-write technique and inviting children to take part. Ethical approval was granted by the Clinical Research Ethics Committee of the Cork Teaching Hospitals. 


\section{Data collection}

Semi-structured interviews

All participants were invited to take part in face-to-face interviews. However, due to time and scheduling difficulties a mixture of telephone and face-to-face interviews were conducted. Semi-structured topic guides were developed based on literature and thorough discussion with international experts. The topic guide for PHN covered their experience of referring parents to W28GOcommunity, their thoughts on the factors influencing initial attendance as well as their views on the value of such a programme in their community. The parent topic guide addressed issues including their experience of the referral process and reasons for attending. Prompts and probes were used throughout the interviews to stimulate discussion.

Prior to each interview, participants were informed about the purpose of the study, that participation was voluntary and that they could terminate the interview at any stage. Signed informed consent was obtained before each interview (for telephone interviews this was obtained via email or by post) and interviews lasted $45 \mathrm{~min}$, on average. Participants were interviewed between August 2015 and February 2016 by E.K. For PHN, data saturation was judged to have been reached between interviews 8 and 9 as no new themes emerged. For parents, saturation occurred after interview 9. No new themes emerged and responses between sites were comparable. Hand-written notes were taken throughout the interviews which were digitally recorded, transcribed verbatim and imported to NVivo QSRv10 software for analysis.

\section{Draw-and-write technique}

The draw-and-write technique ${ }^{(25)}$ is a child-friendly method of collecting data from young children ${ }^{(26)}$ who may have difficulty conveying their feelings verbally ${ }^{(27)}$ and has been used to collect children's views in the health field ${ }^{(25-33)}$. During the final group session, after initial introductions, E.K. provided children with paper, pencils and colours and asked them to draw a picture of 'What they thought was good or bad about the programme'. Upon completion of the drawing, E.K. asked each child to describe it. The child was then asked to title his/her drawing and given a final opportunity to describe it. E.K. noted individual answers for coding purposes. Informed consent was obtained from each child's parent and each child gave his or her assent prior to participation.

\section{Data analysis}

Data were analysed iteratively to explore emergent themes in subsequent interviews. Thematic analysis ${ }^{(34)}$ was conducted in the first instance by E.K. with frequent debriefing sessions with co-authors (S.M.M. and F.S.) to discuss similarities or differences between the coding labels. This process involved reading and re-reading the transcripts several times and resulted in data immersion ${ }^{(34)}$. After familiarisation, data were coded, then codes were examined for patterns and similarities and grouped together to form inductive themes, which were then reviewed and further refined. To ensure the validity and consistency of the findings, four interviews (two PHN and two parents) were coded by two authors not involved in data collection (S.M.M. and F.S.).

\section{Results}

Of the thirteen PHN invited for interview, nine participated (six from site A, three from site B). The reason for non-participation was a lack of time. Of the ninety-four parents who were invited to participate in an interview, ten mothers took part (eight from site A and two from site B). It is important to note that these mothers completed the W82GO-community programme. Two interviews were conducted in person and seventeen were conducted by telephone. Of the fourteen children invited to participate in the research, nine undertook the draw-andwrite component of the study (six from site A, three from site B).

\section{What were public bealth nurses' and parents' experiences of the referral process?}

$\mathrm{PHN}$ and parents reported a number of fears relating to the referral process. For PHN, these fears included misclassifying children as obese and approaching parents about their child's excess weight. For parents, most were afraid of what the referral meant for the health and wellbeing of their child. This concern ultimately outweighed any fears they had prior to accepting the referral.

\section{Public health nurses' fear of misclassifying children as overweight or obese}

PHN felt obesity was an 'enormously sensitive issue' and as a result expressed an overwhelming sense of fear and anxiety regarding the referral process. They spoke of the accuracy and precision required when using BMI growth charts and a common feeling was a 'fear of getting it wrong' and misclassifying children as overweight or obese. As one PHN explained:

'... there was a big fall out from your interpretation so you really needed to be $100 \%$ that you were correct. If you think of the size of the problem you could be landing on a parent's shoulders depending on a small tiny box you're trying to interpret, it's kind of a bridge too far nearly.' (PHN009)

As a result of this fear, PHN found themselves double- and triple-checking at every stage of the screening process:

'You've to check them three or four times. You've got to be in a room on your own and you've got to 
go back and forth. Especially for the ones who were overweight or obese. If they were over the line, I would say I checked them half a dozen times before I sent out the letter because your worst nightmare would be to send out a letter when they weren't, right.' (PHNO03)

The fear and anxiety of getting the diagnosis wrong and the resulting time spent double- and triple-checking led to a call from some PHN for the development of a national standardised BMI app that could be used by all health-care professionals referring children to weight management programmes. Furthermore, in an effort to share the responsibility of referral, PHN suggested community programmes should comprise of open referral pathways:

'It's a lot of pressure being the only ones responsible for referral. There should be an opt-in approach whereby parents could come forward themselves. Referral should be from multiple sources.' (PHN003)

\section{Public bealth nurses' fear of approaching the subject of weight with parents \\ Another reported fear was that of telling parents their child carried excess weight. PHN were afraid of causing upset to families whom they would have to encounter regularly. One PHN stated: \\ '... it was so bad sometimes that I used to bless myself before I went on the phone.' (PHN001)}

The 'dread' felt by PHN was due in part to some PHN having low perceived self-efficacy in discussing weight with parents as well as the verbal abuse some experienced during referral. PHN expressed mixed levels of confidence in addressing weight issues with families. Many spoke of 'feeling drained' at the end of the working day as a result of the telephone calls and outlined a need for more support. Some acknowledged that a quick debrief with other nurses often helped alleviate some of this strain.

All PHN believed that training on how to communicate to parents that their child carried excess weight was needed. While PHN were invited to the W82GO-community training days, they described the training they received as 'too general' and believed they needed more 'practical and tailored' information that was specific to referral. Separate to the implementation of W82GO-community, motivational interviewing (MI) was provided to PHN at one of the two pilot sites. This training appeared to influence PHN confidence in, and readiness to, approach the subject of weight with parents. In site $\mathrm{B}$ where no MI training occurred, PHN spoke of their fear of contacting parents with some 'thankful when they didn't answer the phone' (PHN001). Conversely, in site A, where PHN received MI training specific to childhood obesity, one PHN described how she was not 'frightened of dealing with parents anymore'. She described how as a result of the training she learned:

'... how to explain things in a sensitive, nonjudgemental manner and where to leave pauses for the parent to digest the information.' (PHN009)

Another possible idea suggested by PHN to avoid and reduce such negative initial reactions was to send a letter communicating the results of the screening process to parents on a Friday and advise that the relevant PHN would be in contact during the following week:

'That way parents had time to digest the information over the weekend, so they wouldn't have been as defensive or angry when phoned the following week. It worked well.' (PHN003)

\section{Parental fear of negative consequences of referral}

For parents, the referral process was also one of fear and apprehension. Parents were afraid of the consequences of the referral and what it meant for the health and wellbeing of their child. One parent recalled the referral being 'horrific' and described the letter she received outlining her child's overweight status as 'scary'. In particular, the list of professionals involved in delivering the programme created panic and parents automatically feared the worst in relation to their child's health:

'... a doctor, a physio and worst of all was the psychologist. It sounded like my child was on death's door.' (PARENT004)

The initial fear of the diagnosis was compounded by a difficulty in understanding BMI and the growth charts which were used to explain their child's weight status:

'Something needs to be done about explaining BMI and the chart because for the life of me I couldn't get my head around it. I can imagine some parents thinking it was nonsense drawing someone's height and weight on a chart and coming up with $x$.' (PARENT003).

Even though these parents eventually agreed to participate in W82GO-community, they recalled being afraid of the potential psychological consequences of enrolling their child on a weight management programme. They feared putting a negative 'label' on their child and believed this may have discouraged other parents from enrolling. Some referred to weight as a 'taboo topic' and one described how:

'People were taking it as an offence on themselves. They don't want to be found out as the bad parent.' (PARENT005)

Another recalled the reaction she received from extended family when she told them of her decision to take part in the W82GO-community programme: 
'When I said we were going to go on this programme they looked at me with horror on their faces.' (PARENT010)

\section{Parental denial}

PHN were unanimous in their perception that parental denial was the key driver behind the lack of engagement they experienced during the referral process. They believed obesity has become the norm in society, and as a result parents did not believe their child was carrying excess weight and subsequently declined referral:

'I think there was a denial that there was anything wrong with their child, or that their child was overweight. There was a total denial because the population in general looked like their child. Their child may be a little bit above of what the normal population looks like, but they didn't see that as an issue at all.' (PHN005)

Parents' interviews supported this finding:

'I felt oh for god's sake what are they on about. Because you look at him and you don't see it. I didn't believe it.' (PARENT006)

PHN recalled how parents used terms including 'he's a fine big, heavy boy', 'he was a 10 lb baby', 'he's strong like his father' or 'big-boned like his grandparents' to describe their child's weight in an attempt to justify it. Furthermore, some PHN described how they themselves have become desensitised to the issue:

'Even for some of us health professionals involved there was a sense of shock because they didn't look obese. We have become accustomed to weight over the last couple of years.' (PHN005)

\section{Conflicting messages}

Parents also spoke of how they received conflicting messages in relation to their child's weight status from family, friends and figures of authority including school teachers and general practitioners, and suggested this could possibly undermine other parents' motivation to enrol. Some of the parents who participated in the study recalled how extended family members would question the need to attend such a programme, while one mother recalled attending her own family general practitioner for confirmation of her child's weight status and was told:

'... it's just puppy fat. They checked him over and said it's an age thing, that there was nothing wrong with him.' (PARENT009)

Other parents described the reactions they experienced at the school gate when they told other parents or teachers about the programme:
'She [teacher] just laughed and said not to take any notice of it, that he doesn't look it.' (PARENT006)

\section{Personal and programme logistics}

Finally, PHN spoke of the many personal and programme logistics that parents faced when considering the referral to W82GO-community. These logistics related mainly to conflicting schedules and programme location/lack of transport:

'The initial assessments were during a working day, so parents wanted to reschedule; some wanted an afternoon appointment, some wanted a weekend appointment. Also, they were coming from various locations and that in itself created further barriers in terms of transport, etc.' (PHNO03)

For others, child-minding issues created a barrier to accepting referral:

'There was one child that they wanted to attend with, but they had a small baby at home and they couldn't get child-minders at the time.' (PHN009)

\section{What motivated parents to enrol?}

Despite initial fears, the parents in the present study ultimately chose to participate in, and complete, the W82GOcommunity programme. Reasons included a prevailing concern for their child's future health as well as needing help from a source outside the family. Figure 2 illustrates the key factors influencing parents' decision to enrol in the programme as well as suggestions for improving referral.

\section{Concern for child's future bealth and wellbeing}

Parents described how the 'guilt of doing nothing' or 'fear of future health consequences' motivated them to enrol:

'I kept thinking, heaven forbid down the line if there was a serious problem, no one would help me then and I wouldn't have done anything about it. It would be on my conscience.' (PARENT001)

This parent described how, regardless of how she felt about attending the programme, she would do anything for her child:

'I know if it was for me, I probably wouldn't have gone but when it's for your child it's a different story.' (PARENT001)

'Doing it for your child' was a common theme among parents and this motivation appeared to be more powerful than the initial denial or stigma felt by some parents. While most were concerned for their child's future health, for others emotional issues such as bullying were more salient. These parents were afraid their child would fall victim to bullying in the future should they not accept the referral: 


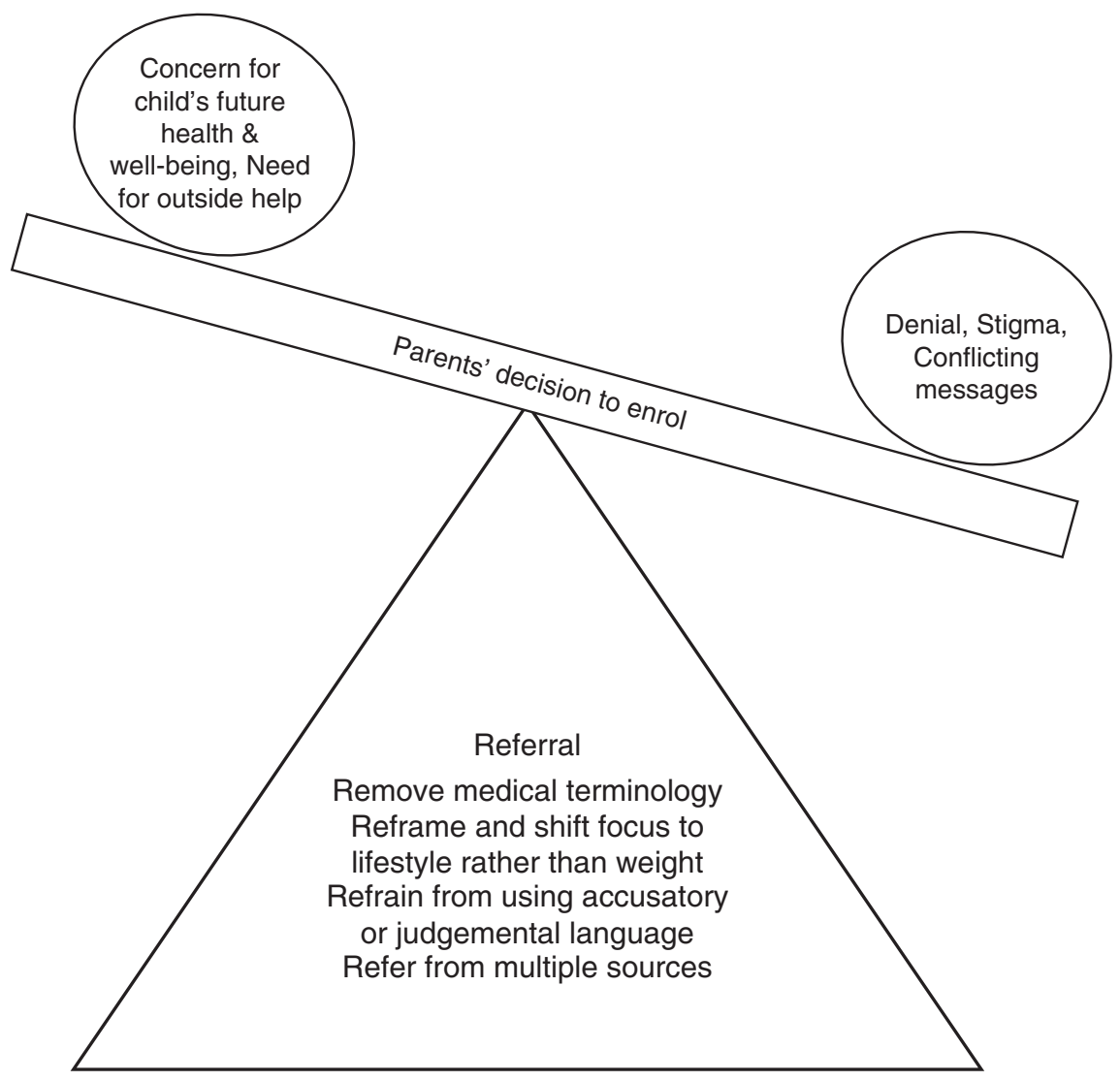

Fig. 2 Factors influencing enrolment and suggestions for improving the referral process

'You don't want your child being bullied because they are overweight. I hear of awful stories in the papers and through friends. I'm not aware of it at this young age but definitely as he gets older it may become a problem and then that leads to all kinds of psychological issues, doesn't it?' (PARENT003)

Finally, parents believed that 5-7 years was a good age to tackle the issue before 'it got out of hand' and became 'something much harder to get a handle on' (PARENT003).

\section{Need for 'outside belp'}

Some of the parents who enrolled in W82GO-community suspected there was an issue with their child's weight but were unsure about how to address it or 'where to go for help'. These parents described feeling relieved when offered the programme and outlined how they needed 'someone from outside the family' to help them make the necessary changes, either because they didn't know what lifestyle changes to make or felt their own efforts weren't being taken seriously by their children:

'I wanted someone to show me how and I suppose I wanted him to hear it from someone else too because he sometimes would only laugh at me. I was delighted to get the extra help.' (PARENT004)

\section{What encourages families to complete the programme?}

Child's enjoyment

Parents reported their children's enjoyment of the programme as the main reason for their continued attendance, with some indicating that they would have dropped out prematurely if it were not for their child having fun:

'I kept going only because they were loving it so much. I didn't love it, they loved it.' (PARENT006)

Parents described how the children had fun, played games and made friends with children of a similar age and ability:

'He looked forward to going to it. He was meeting other boys and girls there and he was having fun. He was having fun and that was a big part of it as well. He loved making new friends and meeting them every week.' (PARENT003)

In addition to making friends, parents believed this enjoyment came from a feeling of being included and excelling in a group where they typically would not, for example in the general school setting. As part of this group, children had the opportunity to be 'team leaders' and one parent described how her son: 
'... used to come out saying he won this race or that he got to choose who was on his team, when you'd never really hear that from him from school. That was a big plus.' (PARENT006)

The importance of having fun was echoed during discussions with the children. During the draw-andwrite component of the study, when asked what they thought about the programme the children focused on the fun they had playing games and making friends with other children, which was also evident in their drawings (Fig. 3). While one child recalled how they were 'always laughing', another described how w82GO-community:

'... was great fun. I loved playing with the big yoga balls and playing with my friends. We do all different games and run up and down and play together.' (CHILD002)

Having enthusiastic staff appeared to foster this fun atmosphere. Parents mentioned the warm welcome their children received each week and how facilitators went to the effort of 'ensuring no one was left out'. For the children in particular, the presence of a male facilitator enhanced their enjoyment:

'... when you get to play with him it's even better.

He's so cool and has got really good skills.' (CHILD007)

Finally, in some cases the presence of a sibling further contributed to a child's enjoyment. Talking about sibling attendance, one parent described how her child would be uncomfortable and shy at first but 'when he saw his sister doing it, he would eventually do it too' (PARENT006). This was confirmed by the children as some described how it helped to reassure them:

'Sometimes I didn't like leaving my mom. I liked it better when my sister came with me.' (CHILD003)

\section{Group support}

Parents also appreciated the friendly atmosphere and social support they received during the group sessions, and a common feeling among parents was the realisation they weren't the 'only ones'. While one mother described how the group component 'was essential because at least you knew then that it's not only you with the problem, that you are all in the same boat' (PARENT001), another spoke of her relief of 'hearing other people's stories and realising it's not just me' (PARENT003). The group sessions afforded parents the opportunity to learn practical 'tips and tricks' and 'do's and don'ts' other parents were using to reinforce healthy lifestyles at home. This shared learning equipped parents with the confidence to try out tactics that worked for others in the group:

'I would have said before I'd never say no to my child and now I do, and I suppose I saw how well it worked for them so I said I would give it a try.' (PARENT007)

As they progressed through the programme, parents became more comfortable with sharing their experiences with one another and believed that:

'No matter what you say there is always one other person in the room that'll know exactly what you are talking about and may even come up with a solution for you - even better!' (PARENT006)

\section{Practical sessions}

Parents preferred practical sessions such as 'dealing with tantrums, saying no and even ideas of activities to do when it's raining' (PARENT006), rather than those sessions utilising a more 'lecture-style' approach, and suggested them as a way to keep parents more engaged. In particular, parents recalled the 'visual sessions' as being the most stimulating. One parent recalled a session on portion
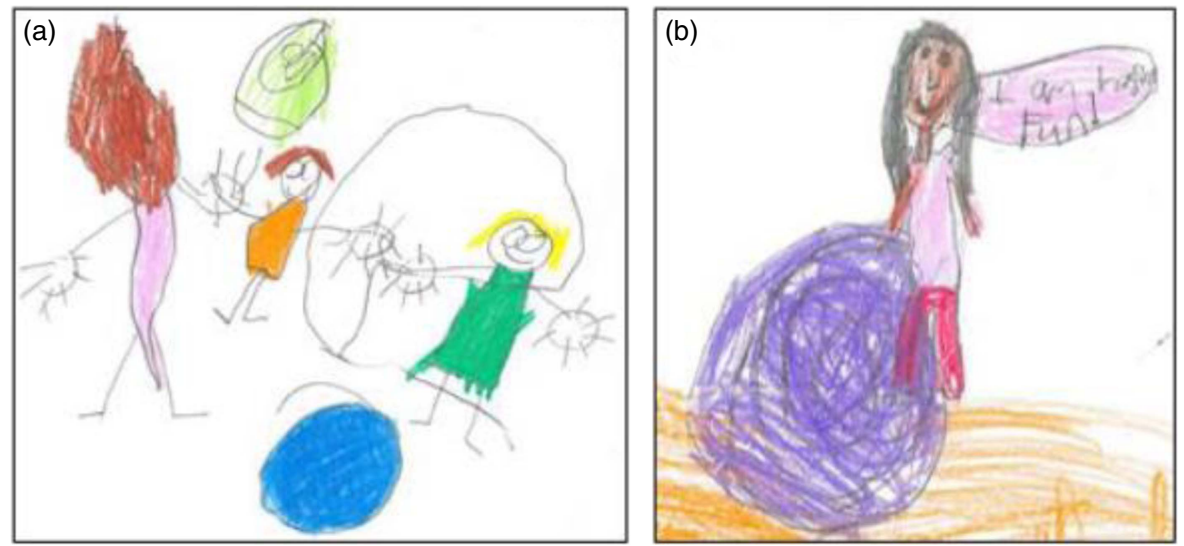

Fig. 3 (colour online) Pictures drawn for the draw-and-write exercise in response to the question, 'What's good and what's bad about coming here each week?': (a) 'playing with new friends' (CHILD002); (b) 'playing games' (CHILD005) 
sizes and described her reaction to seeing what is recommended:

'I was in total shock to see what I had been giving the children and how much they actually needed. It was very, very good ... once you see what a portion is in reality and not what's in your head, you realise. Seeing is believing, I think. A lot of parents were shocked at that and were certainly interested in that aspect of the programme.' (PARENT001)

Some parents confessed they would have liked more of these sessions and suggested they may have enticed others to continue attending:

'I'd have loved to have come away with two or three sample meal plans or shopping lists or what to get in your Chinese takeaway. I think there could have been more practical help. Those practical sessions were brilliant. Sometimes we just listened to a session without being given actual examples and you could see some were getting bored towards the end.' (PARENT004)

\section{Discussion}

The present study aimed to identify and understand, from the perspectives of PHN, parents and children, factors that influence uptake and completion of a community-based, multicomponent, childhood weight management programme. For both PHN and parents an overwhelming sense of fear resided over the referral process. For PHN this related to getting the diagnosis wrong and in relaying results of children's excess weight status to parents. Peer support from other PHN as well as training in delivering the diagnosis were potential strategies suggested to alleviate this fear. When referred to the programme, parents feared the worst because of the technical language used by some PHN but also their inability to interpret the information, particularly BMI charts. Despite these initial fears, parents were driven to participate initially by a concern for their children's future health and well-being. Children's enjoyment was key to encouraging parents to complete the programme. Maximising these factors is essential for the sustainability and spread of community programmes, since enrolment and retention rates remain low, as evidenced internationally ${ }^{(11,13)}$.

Results suggest, and it is also supported in the literature, that a lack of resources (i.e. time and support services) ${ }^{(15,35,36)}$, low perceived self-efficacy ${ }^{(35)}$ and fear of discussing weight issues with parents ${ }^{(35,37)}$ are some of the biggest challenges facing referrers and offer solutions to help overcome such barriers. First, PHN in the present study suggested the need for the development of a BMI app to help reduce the time spent screening children for referral. They felt an app would significantly speed up the process of referral through the automatic calculation of children's BMI-for-age percentiles while also reducing the worry of misclassification. Furthermore, PHN recalled instances where parents used online calculators to determine their child's BMI-for-age resulting in different estimates. As a result, many PHN believed an app could also be used as a resource for parents should they question the results of the screening. Numerous mobile apps are now available to assist health-care professionals in maintaining and accessing health records, patient management and monitoring, clinical decision making, communications and consulting ${ }^{(38-41)}$, and these have been found to enhance $\operatorname{accuracy}^{(38,42)}$, efficiency ${ }^{(42,43)}$ and productivity ${ }^{(38,42)}$. While limited information exists on the effectiveness of an app specific to obesity screening, Surka et al. found their app decreased screening time and eliminated errors in calculating scores relating to CVD risk ${ }^{(44)}$. Second, PHN faced a range of parental responses ${ }^{(16)}$ (e.g. relief, resistance, fear, disinterest, denial or anger) when communicating news of a child's weight status and they should not be expected to manage these responses without the appropriate training. In our study, PHN believed that MI training boosted their confidence and efficacy in communicating 'bad news' regarding obesity. MI is a nonjudgemental, guided, empathetic style of counselling ${ }^{(45)}$, and has been described as a promising approach for health professionals in treating obesity ${ }^{(46,47)}$. In their study, Dawson et al. reported that weight-related MI feedback allowed further time and opportunity for parents to explore their thoughts about excess weight in relation to their child $^{(47)}$. They reported that those parents who received feedback via MI showed a greater increase in concern about their child's weight ${ }^{(47)}$. This is important as we know that increasing parental awareness and recognition of the health risks makes them more likely to engage in behaviour change ${ }^{(48)}$. We therefore recommend that all health-care professionals involved in both the referral to, and delivery of, obesity programmes receive MI training prior to programme commencement.

The PHN and parents who participated in the current qualitative study felt that a lack of parental awareness and/ or denial regarding their child's weight and resistance towards discussing weight issues limited enrolment to W82GO-community. While we were unable to confirm this through interviews with those parents who declined referral, this finding concurs with the literature ${ }^{(13,35,49,50)}$. Parents provided some realistic suggestions to increase enrolment such as toning down the language used in referral letters and removing medical terminology. This finding is supported by Gillespie et al. ${ }^{(51)}$. We recommend all future literature on weight management programmes be reviewed to ensure that every individual can 'obtain, process, and understand basic health information and services needed to make appropriate health decisions $^{, 52,53)}$. In addition to this, in the present study parents suggested moving away from labelling programmes as 
'weight management programmes' and reframing them in a more positive light, such as a 'healthy lifestyle or skillsbased programme for all the family'. Most parents suggested referring to the programme as a 'sports-camp' or 'fit-camp' for 'all the family' as they had done. This finding is consistent with previous research that recommends programmes have a focus on health rather than weight or thinness ${ }^{(54,55)}$. This positive reframing may also encourage those who fear of being stigmatised by others for joining a programme for weight management.

In the current study, only active methods of referral were used for the weight management programme and this required a significant amount of time and resources and resulted in additional strain and pressure for PHN. Recent research suggests that the use of multiple referral strategies (i.e. newspaper, school leaflets, local radio and social media as well as $\mathrm{PHN} /$ general practitioner referral) is advisable, with some directly targeting families and others providing 'blanket coverage ${ }^{, 56,57)}$. Using both methods, as suggested by PHN in the current study, would potentially allow programme staff to enrol parents who are already concerned about their child's weight and those who are not ${ }^{(56)}$. Furthermore, encouraging positive word of mouth, fostering strong links with community groups and distributing printed materials in a range of ways, including within school newspapers, targeted mail-outs and posting in community venues, has been suggested to boost participation and minimise attrition rates to community-based health promotion programmes ${ }^{(58)}$.

The factors motivating families to get involved and complete treatment reported in the present study should be used in efforts to improve attendance. In common with earlier studies, parents cited the fear of doing nothing and a concern for their child's future health and well-being (i.e. name-calling, bullying, social relationships) as reasons for enrolment $^{(13,59)}$. More frequently these reasons outweighed the desire for any weight-related outcomes ${ }^{(59)}$. Health professionals and programme developers need to be aware of the importance of the psychological benefits of attending and highlight them in any programme-related marketing activities. Finally, to appeal to parents, a familybased programme that facilitates sibling involvement and includes practical and visual sessions with an emphasis on lifestyle was suggested by both parents and staff.

\section{Limitations of the current study}

A major limitation of the current study was the failure to recruit non-attenders or those families who dropped out of treatment despite the provision of an incentive and reminders. As might be expected, this is not uncommon and similar studies of family-focused childhood weight management programmes also had low response rates from this hard-to-reach group ${ }^{(60,61)}$. Despite this limitation we believe the mothers we interviewed were open in their responses about what worked well for them and what did not work so well. Additionally, recall bias is possible since we interviewed PHN and parents twelve months after programme referral.

\section{Conclusion}

Childhood obesity is a complex and sensitive issue worldwide. The present study provides evidence of the difficulties of referring families to community weight management programmes and key factors influencing their initial and continued attendance. It also provides some practical suggestions on how to support those referring children and their families and provides evidence on the factors that contribute to the uptake of community weight management programmes. Policy makers need to recognise childhood obesity as a serious public health issue and allocate appropriate resources to support the evidence-based management of obesity through practical training and education in the area of childhood obesity and related lifestyle issues.

\section{Acknowledgements}

Acknowledgements: The authors are grateful to the PHN, parents and children who agreed to participate the study; without them, this research would not have been possible. Financial support: E.K. is funded by the Health Research Board (grant number SPHeRE/2013/1). 'The Health Research Board (HRB) supports excellent research that improves people's health, patient care and health service delivery. We aim to ensure that new knowledge is created and then used in policy and practice. In doing so, we support health system innovation and create new enterprise opportunities.' S.M.M. is funded by the Centre for Ageing Research and Development in Ireland (CARDI), now the Ageing Research and Development Division within the Institute of Public Health in Ireland (IPH). HRB and IPH had no role in the design, analysis or writing of this article. Conflict of interest: No competing interests exist. Authorship: E.K. was responsible for the design and conduct of the research and writing of the manuscript. S.M.M. and F.S. were involved in data analysis and reviewed drafts of the manuscript. E.K., S.M.M., J.M.H., F.S. and I.J.P. made critical revisions to the paper and gave final approval of the version to be submitted. Ethics of human subject participation: This study was conducted according to the guidelines laid down in the Declaration of Helsinki and all procedures involving human subjects were approved by the Clinical Research Ethics Committee of the Cork Teaching Hospitals. Written informed consent was obtained from all subjects. 


\section{References}

1. Olds T, Maher C, Zumin S et al. (2011) Evidence that the prevalence of childhood overweight is plateauing: data from nine countries. Int J Pediatr Obes 6, 342-360.

2. Skinner A, Perrin E \& Skelton J (2016) Prevalence of obesity and severe obesity in US children, 1999-2014. Obesity (Silver Spring) 24, 1116-1123.

3. Keane E, Kearney P, Perry I et al. (2014) Trends and prevalence of overweight and obesity in primary school aged children in the Republic of Ireland from 2002-2012: a systematic review. BMC Public Health 14, 974.

4. Butland B, Jebb S, Kopelman P et al. (2007) Tackling Obesities: Future Choices - Project Report. London: Government Office for Science, Foresight Programme.

5. Singh AS, Mulder C, Twisk JWR et al. (2008) Tracking of childhood overweight into adulthood: a systematic review of the literature. Obes Rev 9, 474-488.

6. Lobstein T \& Jackson-Leach R (2006) Estimated burden of paediatric obesity and co-morbidities in Europe. Part 2. Numbers of children with indicators of obesity-related disease. Int J Pediatr Obes 1, 33-41.

7. Bleich S, Segal J, Wu Y et al. (2013) Systematic review of community-based childhood obesity prevention studies. Pediatrics 132, e201-e210.

8. National Institute for Health and Clinical Excellence (2015) Obesity. Guidance on the Prevention of Overweight and Obesity in Adults and Children. NICE Clinical Guideline no. 43. London: NICE.

9. Oude Luttikhuis H, Baur L, Jansen H et al. (2009) Interventions for treating obesity in children. Cochrane Database Syst Rev issue 1, CD001872.

10. World Health Organization (2016) Report of the Commission on Ending Childhood Obesity. Geneva: WHO Document Production Services.

11. Skelton J \& Beech B (2011) Attrition in paediatric weight management: a review of the literature and new directions. Obes Rev 12, e273-e281

12. Robertson W, Fleming J, Kamal A et al. (2016) Randomised controlled trial and economic evaluation of the 'Families for Health' programme to reduce obesity in children. Arch Dis Child 102, 416-426.

13. Kelleher E, Davoren M, Harrington J et al. (2017) Barriers and facilitators to initial and continued attendance at community-based lifestyle programmes among families of overweight and obese children: a systematic review. Obes Rev 18, 183-194.

14. Perez A, Avis J, Holt N et al. (2016) Why do families enrol in paediatric weight management? A parental perspective of reasons and facilitators. Child Care Health Dev 42, 278-287.

15. Steele R, Wu Y, Jensen C et al. (2011) School nurses' perceived barriers to discussing weight with children and their families: a qualitative approach. J Sch Health 81, 128-137.

16. Mikhailovich K \& Morrison P (2007) Discussing childhood overweight and obesity with parents: a health communication dilemma. J Child Health Care 11, 311-322.

17. Skelton J, Irby M, Beech B et al. (2012) Attrition and family participation in obesity treatment programs: clinicians' perceptions. Acad Pediatr 12, 420-428.

18. Braet C, Jeannin R, Mels S et al. (2010) Ending prematurely a weight loss programme: the impact of child and family characteristics. Clin Psychol Psychother 17, 406-417.

19. Ball G, Garcia A, Chanoine J et al. (2012) Should I stay or should I go? Understanding families' decisions regarding initiating, continuing, and terminating health services for managing pediatric obesity: the protocol for a multi-center, qualitative study. BMC Health Serv Res 12, 486.

20. Cote M, Byczkowski T, Kotagal U et al. (2004) Service quality and attrition: an examination of a pediatric obesity program. Int J Qual Health Care 16, 165-173.
21. Bryant M, Burton W, Cundill B et al. (2017) Effectiveness of an implementation optimisation intervention aimed at increasing parent engagement in HENRY, a childhood obesity prevention programme - the Optimising Family Engagement in HENRY (OFTEN) trial: study protocol for a randomised controlled trial. Trials 18, 40.

22. O'Malley G, Brinkley A, Moroney K et al. (2012) Is the Temple Street W82GO Healthy Lifestyles Programme effective in reducing BMI SDS? Obes Facts 5, Suppl. 1, $178-234$.

23. National Institute for Health and Clinical Excellence (2013) Weight Management: Lifestyle Services for Overweight or Obese Children and Young People. NICE Clinical Guideline no. 47. London: NICE.

24. Cole T, Freeman J \& Preece M (1995) Body mass index reference curves for the UK, 1990. Arch Dis Child 73, 25-29.

25. Pridmore P \& Bendelow G (1995) Images of health: exploring beliefs of children using the 'draw-and-write' technique. Health Educ J 54, 473-488.

26. Bradding A \& Horstman M (1999) Using the write and draw technique with children. Eur J Oncol Nurs 3, 170-175.

27. Hill M, Laybourn A \& Borland M (1996) Engaging with primary-aged children about their emotions and well-being: methodological considerations. Child Soc 10, 129-144.

28. Williams D, Wetton N \& Moon A (1989) A Way In: Five Key Areas of Health Education. London: Health Education Authority.

29. Piko BF \& Bak J (2006) Children's perceptions of health and illness: images and lay concepts in preadolescence. Health Educ Res 21, 643-653.

30. Rollins J (2005) Tell me about it: drawing as a communication tool for children with cancer.J Pediatr Oncol Nurs 22, 203-221.

31. Gross J \& Hayne H (1998) Drawing facilitates children's verbal reports of emotionally laden events. $J$ Exp Psychol Appl 4, 163-179.

32. Horstman M, Aldiss S, Richardson A et al. (2008) Methodological issues when using the draw and write technique with children aged 6 to 12 years. Qual Health Res 18, 1001-1011.

33. Walker K, Caine-Bish N \& Wait S (2009) 'I like to jump on my trampoline': an analysis of drawings from 8- to 12-yearold children beginning a weight-management program. Qual Health Res 19, 907-917.

34. Braun V \& Clarke V (2006) Using thematic analysis in psychology. Qual Res Psychol 3, 77-101.

35. Gerards SM, Dagnelie P, Jansen M et al. (2012) Barriers to successful recruitment of parents of overweight children for an obesity prevention intervention: a qualitative study among youth health care professionals. BMC Fam Pract 13, 37.

36. Kubik M, Story M \& Davey C (2007) Obesity prevention in schools: current role and future practice of school nurses. Prev Med 44, 504-507.

37. Moyers P, Bugle L \& Jackson E (2005) Perceptions of school nurses regarding obesity in school-age children. J Sch Nurs 21, 86-93.

38. Aungst T (2013) Medical applications for pharmacists using mobile devices. Ann Pharmacother 47, 1088-1095.

39. Ozdalga E, Ozdalga A \& Ahuja N (2012) The smartphone in medicine: a review of current and potential use among physicians and students. J Med Internet Res 14, e128.

40. Mosa A, Yoo I \& Sheets L (2012) A systematic review of healthcare applications for smartphones. BMC Med Inform Decis Mak 12, 67.

41. Wallace S, Clark M \& White J (2012) 'It's on my iPhone': attitudes to the use of mobile computing devices in medical education, a mixed-methods study. BMJ Open $\mathbf{2}$, e001099. 
42. Mickan S, Tilson J, Atherton $\mathrm{H}$ et al. (2013) Evidence of effectiveness of health care professionals using handheld computers: a scoping review of systematic reviews. J Med Internet Res 15, e212.

43. Kiser K (2011) 25 ways to use your smartphone. Physicians share their favorite uses and apps. Minn Med 94, 22-29.

44. Surka S, Edirippulige S, Steyn K et al. (2014) Evaluating the use of mobile phone technology to enhance cardiovascular disease screening by community health workers. Int J Med Inform 83, 648-654.

45. Miller W \& Rollnick S (2002) Motivational Interviewing: Preparing People for Change. New York: The Guilford Press.

46. Borrello M Pietrabissa G, Ceccarini M et al. (2015) Motivational interviewing in childhood obesity treatment. Front Psychol 6, 1732.

47. Dawson A, Brown D, Cox A et al. (2014) Using motivational interviewing for weight feedback to parents of young children. J Paediatr Child Health 50, 461-470.

48. Rhee K, De Lago C, Arscott-Mills T et al. (2005) Factors associated with parental readiness to make changes for overweight children. Pediatrics 116, e94-e101.

49. Grow H, Hsu C, Liu L et al. (2013) Understanding family motivations and barriers to participation in communitybased programs for overweight youth: one program model does not fit all. J Public Health Manag Pract 19, E1-E10.

50. Kelleher E, Harrington J, Shiely F et al. (2017) Barriers and facilitators to the implementation of a community-based, multidisciplinary, family-focused childhood weight management programme in Ireland: a qualitative study. BMJ Open 7, e016459.

51. Gillespie J, Midmore C, Hoeflich J et al. (2015) Parents as the start of the solution: a social marketing approach to understanding triggers and barriers to entering a childhood weight management service. J Hum Nutr Diet 28, Suppl. 1, 83-92.
52. Ratzan S \& Parker R (2000) Introduction. In Current Bibliographies in Medicine: Health Literacy, No. 2001-1, pp. v-vii. Bethesda, MD: National Library of Medicine Reference Section.

53. Marshall S, Sahm L \& McCarthy S (2012) Health literacy in Ireland: reading between the lines. Perspect Public Health 132, 31-38.

54. Puhl R \& Latner J (2007) Stigma, obesity, and the health of the nation's children. Psychol Bull 133, 557-580.

55. Smith K, Straker L, McManus A et al. (2014) Barriers and enablers for participation in healthy lifestyle programs by adolescents who are overweight: a qualitative study of the opinions of adolescents, their parents and community stakeholders. BMC Pediatr 14, 53.

56. Fleming J, Kamal A, Harrison E et al. (2015) Evaluation of recruitment methods for a trial targeting childhood obesity: Families for Health randomised controlled trial. Trials 16, 535.

57. Nguyen B, McGregor K, O'Connor J et al. (2012) Recruitment challenges and recommendations for adolescent obesity trials. J Paediatr Child Health 48, 38-43.

58. Centre for Physical Activity and Nutrition Research (2012) Identifying Effective Strategies to Increase Recruitment and Retention in Community-Based Health Promotion Programs. Melbourne: Deakin University.

59. Stewart L, Chapple J, Hughes AR et al. (2008) Parents' journey through treatment for their child's obesity: a qualitative study. Arch Dis Child 93, 35-39.

60. Lucas P, Curtis-Tyler K, Arai L et al. (2014) What works in practice: user and provider perspectives on the acceptability, affordability, implementation, and impact of a family-based intervention for child overweight and obesity delivered at scale. BMC Public Health 14, 614.

61. Barratt R, Levickis $P$, Naughton G et al. (2013) Why families choose not to participate in research: feedback from nonresponders. J Paediatr Child Health 49, 57-62. 